\title{
Radiation-induced expression of IER5 is dose-dependent and not associated with the clinical outcomes of radiotherapy in cervical cancer
}

\author{
HAI-MIN SHI ${ }^{1}$, KU-KE DING ${ }^{2}$, PING-KUN ZHOU ${ }^{3}$, DONG-MEI GUO ${ }^{1}$, DAN CHEN $^{1}$, \\ YAN-SHA LI $^{1}$, CHUN-LI ZHAO ${ }^{1}$, CHEN-CHEN ZHAO ${ }^{1}$ and XIN ZHANG ${ }^{1}$ \\ ${ }^{1}$ Department of Gynaecology, Liaoning Cancer Hospital and Institute, Shenyang, Liaoning 110042; \\ ${ }^{2}$ National Institute for Radiological Protection, Chinese Center for Disease Control and Prevention, Beijing 100088; \\ ${ }^{3}$ Department of Radiation Toxicology and Oncology, Beijing Institute of Radiation Medicine, Beijing 100850, P.R. China
}

Received November 27, 2014; Accepted October 30, 2015

DOI: $10.3892 / \mathrm{ol} .2016 .4086$

\begin{abstract}
This study aimed to investigate the expression of the immediate-early response 5 (IER5) gene in cervical cancer tissues and explore the association between the expression of IER5 and the clinical outcomes of radiotherapy. We collected specimens by surgery or biopsy and obtained 53 specimens from tissues after radiotherapy and 16 specimens from tissues before radiotherapy. Immunohistochemistry and western blotting were used to assess the protein expression levels of IER5. Quantitative polymerase chain reaction (qPCR) was performed to assess the mRNA expression levels of IER5. The protein and mRNA expression levels of IER5 in cervical cancer patients treated with radiation doses $\geq 20$ Gy were significantly higher than in those treated with radiation doses $<20 \mathrm{~Gy}(\mathrm{P}<0.05)$ and before treatment with radiotherapy. Moreover, the expression of IER 5 was significantly positively correlated with the radiation dose (immunohistochemistry: $\mathrm{r}=0.548, \mathrm{P}=0.019$; qPCR: $\mathrm{r}=0.671, \mathrm{P}=0.002$; western blotting: $\mathrm{r}=0.573, \mathrm{P}<0.0001)$. Radiotherapy induced the upregulated expression of IER5 and this was dependent on the radiation dose. However, the radiation-induced expression of IER 5 was not associated with the clinical outcomes of radiotherapy in cervical cancer.
\end{abstract}

\section{Introduction}

Cervical cancer, which is associated with sexual, bowel and bladder function, is caused by the infection of the human papillomavirus in $99.8 \%$ of cases (1). It is the leading malignancy among females and a common cause of mortality among

Correspondence to: Dr Xin Zhang, Department of Gynaecology, Liaoning Cancer Hospital and Institute, 44 The River Road, Dadong, Shenyang, Liaoning 110042, P.R. China

E-mail: xinzhangzh@163.com

Key words: cervical cancer, IER5, immunohistochemistry, quantitative polymerase chain reaction, western blotting middle-aged females (2,3). Statistics have revealed that in 2008, the incidence and mortality rates were $9.0 \%$ and $3.2 \%$ in more developed areas, and $17.8 \%$ and $9.8 \%$ in less developed areas, respectively (4). The estimated numbers of new cases and mortalities, which have been increasing in recent years, reached 12,360 and 4,020, respectively, in 2014 in the United States (5-7). In view of these figures, it is essential to the health of females to improve the efficacy of treatment for cervical cancer.

At present, radiotherapy continues to be the cornerstone in the treatment of cervical cancer $(8,9)$. However, the radiosensitivity of cervical cancer cells, which is associated with genetic factors, restricts the efficacy of radiotherapy (10). Thus, it is essential to investigate the mechanism of radiosensitivity of cervical cancer cells in order to improve the efficacy of radiotherapy. It was reported that radiotherapy-induced expression of encoding immediate-early response 5 gene (IER5) affected the radiosensitivity of HeLa cells by disturbing radiation-induced cell cycle checkpoints $(11,12)$. In addition, it was reported that the radiation-induced expression of IER5 in human lymphoblastoid cells was dose-dependent $(13,14)$. Thus, we speculated that the expression of IER5 might be also induced by radiotherapy, and then correlated the efficacy of radiotherapy through its influence on radiosensitivity in cervical cancer cells.

However, no studies exist concerning the correlation between radiotherapy-induced expression of IER 5 and the efficacy of radiotherapy in cervical cancer. Thus, we investigated the expression of IER5 in cervical cancer patients treated with various radiation doses to explore the association between the expression of IER5 and radiotherapy. In addition, the correlation between the expression of IER5 and clinical outcomes of radiotherapy was also analyzed. These investigations are likely to provide a new direction for assessing the improvement and predicting the clinical outcomes of radiotherapy in treating cervical cancer.

\section{Materials and methods}

Patients and treatment. A total of 53 cervical cancer patients aged between 47 and 68 years old (average, 58.3 \pm 3.2 ) and 
treated in the Department of Gynecology, Liaoning Cancer Hospital and Institute, China, between October 2011 and July 2013 were included in this study. The inclusion criteria were: i) patients were first diagnosed and treated; ii) patients were diagnosed with cervical squamous cell carcinoma by biopsy; iii) patients were in clinical stage II-III of cervical cancer based on the International Federation of Gynecology and Obstetrics (FIGO) cancer staging system (15); iv) the results of complete blood count (CBC), urinalysis, electrocardiogram, and liver and kidney function tests were normal; v) there were no contraindications to radiotherapy in the patients. The exclusion criteria were: i) patients had bone marrow suppression with white blood cells less than $3 \times 10^{9} / 1^{-1}$ and platelets less than $7 \times 10^{9} / 1^{-1}$ in the CBC examination; ii) patients had complications due to other critical diseases, including serious cardiovascular and cerebrovascular diseases, acute hepatitis and uremia; iii) acute or subacute pelvic inflammatory disease was not under control.

All the included patients were treated with pelvic external irradiation by a 10-MV X-ray at a dose of 180-200 centigrays (cGy) once a day and five times a week. The treatment was continued until all tumors had fully regressed. For all patients, the maximum cumulative dose of radiation was $50 \mathrm{~Gy}$.

The study was approved by the Liaoning Provincial Tumor Hospital Ethics Committee and all included patients provided their informed consent.

Specimen collection. The 3-5 $\mathrm{mm}^{3}$ cervical cancer tissues of patients were obtained by surgery or biopsy before and after radiotherapy. Each fresh tissue was immediately placed into an Eppendorf tube (RNase-free; Eppendorf, Hamburg, Germany) and preserved in liquid nitrogen. As a result, a total of $53 \mathrm{spec}-$ imens from tissues after radiotherapy and 16 specimens from tissues before radiotherapy were obtained. According to the cumulative dose of radiation, the specimens were randomly divided into three groups: the 0 Gy group (16 specimens which were obtained from tissues before radiotherapy), the $<20 \mathrm{~Gy}$ group ( 20 specimens) and the $\geq 20$ Gy group ( 33 specimens).

Immunohistochemistry. The immunohistochemical staining was performed using a SuperPolymer rabbit and mouse horseradish peroxidase (HRP) kit (CoWin Bioscience Co., Ltd., Beijing, China). Firstly, 4- $\mu \mathrm{m}$ paraffin-embedded sections were deparaffinized with xylene and dehydrated in alcohol. The sections were then subjected to microwave antigen retrieval in $10 \mathrm{mM}$ sodium citrate buffer at $\mathrm{pH} 6$ (CoWin Bioscience Co., Ltd.) for $10 \mathrm{~min}$. After cooling for $20 \mathrm{~min}$ and washing in phosphate-buffered saline (PBS), these sections were immersed in methanol with $0.3 \%$ hydrogen peroxide for $10 \mathrm{~min}$ to inactivate endogenous peroxidase activity, followed by normal horse and goat serum for 30 min to block non-specific reactions. Secondly, these sections were incubated in primary antibody solution (1:20) for $60 \mathrm{~min}$. After washing with PBS, they were incubated with secondary antibody solution for $10 \mathrm{~min}$ at room temperature. Then sections were rewashed with PBS and incubated with streptavidin-HRP solution for $10 \mathrm{~min}$ at room temperature. Finally, sections were stained with 3,3-diaminobenzidine solution and counterstained with hematoxylin (CoWin Bioscience Co., Ltd.). In addition, the PBS instead of the primary antibody solution was considered as the negative control. Color images of immunohistochemically stained sections were captured with a microscopic imaging system (Leica Q500MC; Leica, Cambridge, UK). The shade of positive tissue staining was observed, with brown color representing positive expression of IER5 protein. The optical density (OD) value of positive tissue staining was measured and analyzed using an Alpha Imager 2000 (Alpha Innotech Corp., CA, USA).

RNA extraction and reverse transcription. Frozen samples were thawed, and then total RNA was extracted using TRIzol (Invitrogen Life Technologies, Carlsbad, CA, USA). The quantity and quality of RNA were analyzed by NanoDrop (NanoDrop Technologies, Wilmington, DE, USA) using 260/280 nm and gel analysis. Moreover, pretreatment of the RNA samples with RNAse-free DNAse was conducted to avoid genetic DNA causing false positive amplifications (16). Complementary DNA (cDNA) was synthesized from RNA using a reverse transcription kit (Toyobo Biotech Co., Ltd., Shanghai, China) according to the manufacturer's instructions. The reaction conditions were $37^{\circ} \mathrm{C}$ for $15 \mathrm{~min}$, followed by $50^{\circ} \mathrm{C}$ for $5 \mathrm{~min}$ and $98^{\circ} \mathrm{C}$ for $5 \mathrm{~min}$.

Quantitative polymerase chain reaction $(q P C R)$. $\mathrm{qPCR}$ was performed using a real-time PCR instrument (Bio-Rad Laboratories, Hercules, CA, USA) and data were analyzed by MJ Opticon Monitor software (Bio-Rad Laboratories). IER5 and $\beta$-actin were used as shown in Table I. The reactions were carried out in a volume of $20 \mu \mathrm{l}$ containing $9 \mu \mathrm{l}$ 2.5X Real Master mix/20X SYBR solution, $4 \mu$ l each primer, $0.33 \mu \mathrm{l}$ cDNA template and $6.77 \mu \mathrm{l}$ nuclease-free water. The amplification of cDNA was started with an initial denaturation step at $95^{\circ} \mathrm{C}$ for $1 \mathrm{~min}$, then 40 consecutive cycles of the following series of steps were performed: denaturation at $95^{\circ} \mathrm{C}$ for $30 \mathrm{sec}$, annealing at $63^{\circ} \mathrm{C}$ for $45 \mathrm{sec}$ and extension at $68^{\circ} \mathrm{C}$ for $45 \mathrm{sec}$. Results were collected and analyzed with MJ Opticon Monitor analysis software. The comparative $\mathrm{Ct}$ method $(\Delta \Delta \mathrm{Ct})$ was used for quantification of gene expression. The relative expression was calculated as $2^{-\Delta \Delta \mathrm{Ct}}$ according to the Perkin Elmer Instruction Manual (17), where $\Delta \Delta \mathrm{Ct}=[\mathrm{Ct}$ (IER5) - Ct ( $\beta$-actin) $-[\mathrm{Ct}$ (IER5, calibrator) - $\mathrm{Ct}(\beta$-actin, calibrator)].

Western blotting. Frozen tissue samples were pulverized under liquid nitrogen using a mortar and pestle immersed in liquid nitrogen. Then tissue cells were lysed on ice by using protein lysates (CoWin Bioscience Co., Ltd.) and phenylmethylsulfonyl fluoride (CoWin Bioscience Co., Ltd.). Cell disruption was performed in an ice bath using an ultrasonic processor (Q700 Sonicator; Qsonica, LLC, Newtown, CT, USA) for $5 \mathrm{~min}$. The proteins were released after cell disruption. Protein content was quantitated using a bicinchoninic acid protein assay kit (Tiangen Biotech Co., Ltd., Beijing, China). Western blotting was performed as follows. Firstly, proteins were heated for 2 min in a boiling water bath prior to loading on a sodium dodecyl sulfate (SDS) polyacrylamide gel (12\%), and then electrophoretically transferred to a nitrocellulose membrane. After blocking, membranes were incubated overnight at $4^{\circ} \mathrm{C}$ with goat polyclonal anti-IER5 (1:500; Abcam Inc., Cambridge, MA, USA) or mouse anti- $\beta$-actin (1:1000; Santa 
Table I. Primers of IER5 and $\beta$-actin.

\begin{tabular}{lll}
\hline Gene name & Forward primer $\left(5^{\prime} \rightarrow 3^{\prime}\right)$ & Reverse primer $\left(5^{\prime} \rightarrow 3^{\prime}\right)$ \\
\hline IER5 & GGACGACACCGACGAGGAG & GCTTTTCCGTAGGAGTCCCG \\
$\beta$-actin & GCGCGGCTACAGCTTCA & CTTAATGTCACGCACTTTCC
\end{tabular}

IER5, immediate-early response 5 .

Table II. mRNA and protein expression of IER5 in each group.

\begin{tabular}{lccc}
\hline Groups & $\begin{array}{c}\text { Immunohistochemistry } \\
\text { expression levels of IER5 protein }\end{array}$ & $\begin{array}{c}\text { qPCR mRNA } \\
\text { expression of IER5 }\end{array}$ & $\begin{array}{c}\text { Western gray scale } \\
\text { ratio of IER5/ } \beta \text {-actin }\end{array}$ \\
\hline 0 Gy group & $0.241 \pm 0.030$ & $0.813 \pm 0.145$ & $0.653 \pm 0.154$ \\
$<20$ Gy group & $0.239 \pm 0.014$ & $0.785 \pm 0.238$ & $0.847 \pm 0.359$ \\
$\geq 20$ Gy group & $0.272 \pm 0.019^{\mathrm{a}, \mathrm{b}}$ & $1.227 \pm 0.216^{\mathrm{a}, \mathrm{b}}$ & $1.300 \pm 0.376^{\mathrm{a}, \mathrm{b}}$
\end{tabular}

IER5, immediate-early response 5. qPCR, quantitative polymerase chain reaction. ${ }^{\mathrm{a} C o m p a r e d}$ with 0 Gy group, $\mathrm{P}<0.05$; ${ }^{\mathrm{b}} \mathrm{Compared}$ with $<20$ Gy group, $\mathrm{P}<0.05$.

Cruz Biotechnology, Inc., Santa Cruz, CA, USA) monoclonal antibody. Afterwards, membranes were washed three times with Tris-buffered saline containing $0.05 \%$ Tween-20 (8 min each time) before and after incubating with anti-goat $\mathrm{IgG}$ and anti-mouse $\mathrm{IgG}$ for $1 \mathrm{~h}$ at room temperature (1:1000, Santa Cruz Biotechnology, Inc.). Finally, the membrane was assayed using an enhanced chemiluminescent kit (ECL; Thermo Scientific, Rockford, IL, USA) and scanned with a ChemiDoc ${ }^{\mathrm{TM}}$ Doc $\mathrm{XRS}+$ system (Bio-Rad Laboratories). The relative protein content was represented through the gray value ratio of IER5 protein bands/ $\beta$-actin protein bands, and the results were analyzed with Quantity One software (Version 4.3.0, Bio-Rad Laboratories).

Follow-up. The outcomes of treatment were obtained by telephone follow-up or medical record review with the deadline of March 2014. The survival and recurrence rate during the follow-up were calculated.

Data analysis. Data are presented as the means \pm standard deviation. The data were analyzed by using the SPSS statistical package 19.0 (IBM SPSS, Armonk, NY, USA). One-way analysis of variance was used to compare differences among groups. The least significant difference method was used to test the difference between groups. Spearman's rank correlation method was used to assess the association. A likelihood ratio Chi-square test was used to compare the difference between two values. For all above statistical analyses, $\mathrm{P}<0.05$ was considered to indicate a statistically significant difference.

\section{Results}

Immunohistochemistry analysis. A total of 18 tissue specimens (0 Gy group, 6 specimens; <20 Gy group, 4 specimens; $\geq 20$ Gy group, 8 specimens) were randomly selected for the immunohistochemistry analysis. We observed that the brown staining was increasingly deep with the increase of radiation dose in immunohistochemically stained sections (Fig. 1), indicating that the protein expression level of IER 5 was raised with the increase in radiation dose. For the OD values, there was no significant difference between the 0 Gy and $<20$ Gy groups (0 Gy group, 0.241 $\pm 0.030 ;<20$ Gy group, 0.239 \pm 0.014 ; $\mathrm{P}=0.915$; Table II). However, the protein expression level of IER 5 in the $\geq 20$ Gy group was significantly higher than that in the other two groups ( $\geq 20$ Gy group, $0.272 \pm 0.019$; compared with $<20$ Gy group, $\mathrm{P}=0.030$; compared with 0 Gy group, $\mathrm{P}=0.021$; Table II). Moreover, the results of the correlation analysis indicated that there was a significant positive correlation between the protein expression of IER5 and the dose of radiation $(\mathrm{r}=0.548, \mathrm{P}=0.019)$.

mRNA level of IER5. A total of 18 tissue specimens (0 Gy group, 6 specimens; $<20$ Gy group, 4 specimens; $\geq 20$ Gy group, 8 specimens) were randomly selected for qPCR. The results revealed that there was no significant difference between the 0 Gy and <20 Gy groups (0 Gy group, $0.813 \pm 0.145 ;<20$ Gy group, 0.785 $\pm 0.238 ; \mathrm{P}=0.830$; Table II). However, the mRNA level of IER 5 in the $\geq 20$ Gy group was significantly higher than that in the other two groups $(\geq 20$ Gy group, 1.227 \pm 0.216 ; compared with $<20$ Gy group, $\mathrm{P}=0.003$; compared with 0 Gy group, $\mathrm{P}=0.002$; Table II). In addition, the results of the correlation analysis indicated that there was a significant positive correlation between the mRNA expression of IER5 and the dose of radiation $(\mathrm{r}=0.671, \mathrm{P}=0.002)$.

Western blotting. A total of 33 tissue specimens (0 Gy group, 4 specimens; <20 Gy group, 12 specimens; $\geq 20$ Gy group, 17 specimens) were randomly selected for western blot analysis. The results of SDS-polyacrylamide gel electrophoresis are shown in Fig. 2. Based on the gray scale ratio of IER $5 / \beta$-actin, 

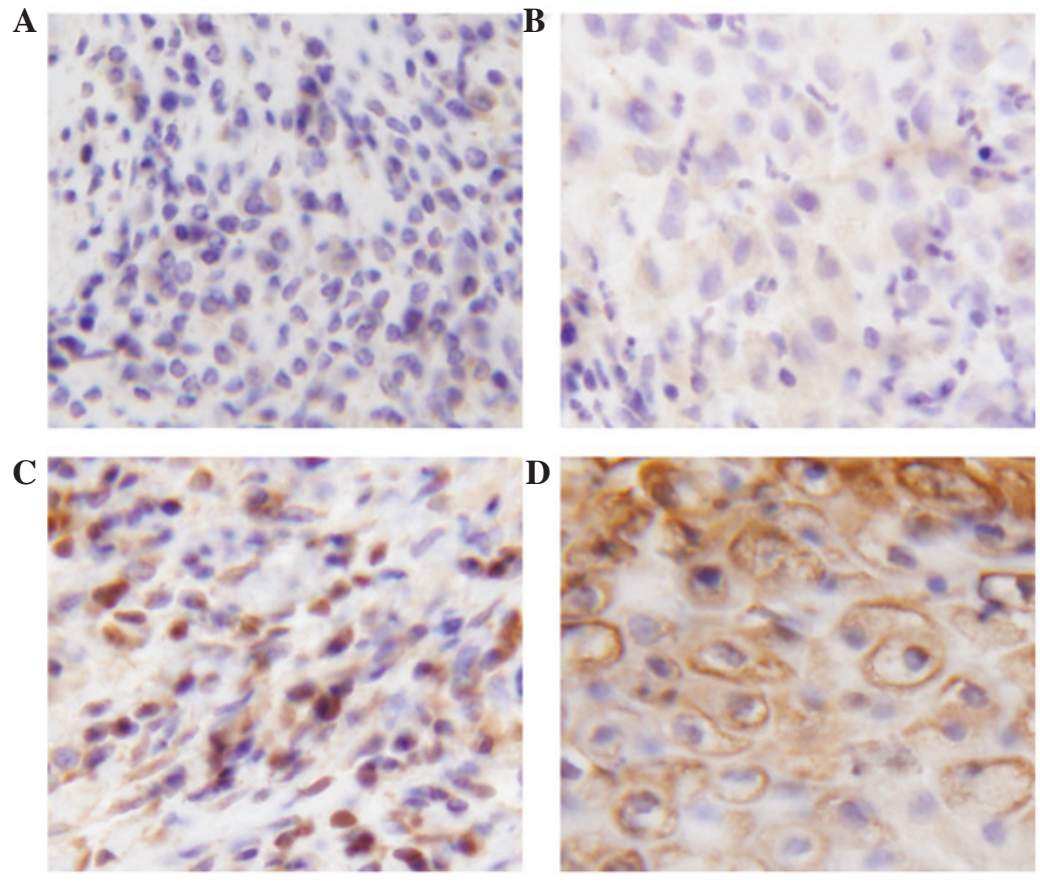

Figure 1. Immunohistochemically stained tumor sections from patients treated with (A) 0, (B) 7, (C) 30 and (D) 50 Gy radiation (3,3'-diaminobenzidine and hematoxylin staining; magnification, $\mathrm{x} 40$ ).
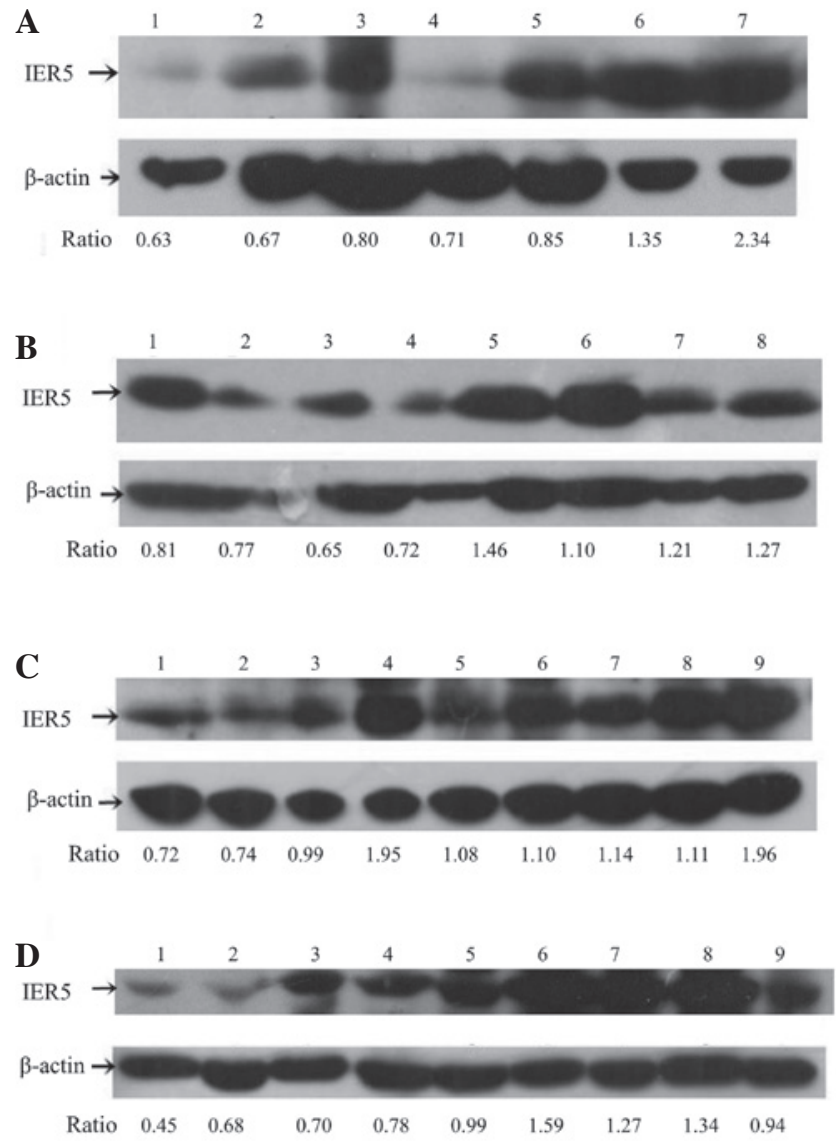

Figure 2. Results of sodium dodecyl sulfate polyacrylamide gel electrophoresis of immediate-early response 5 (IER5) and $\beta$-actin. (A) 1, $0 \mathrm{~Gy} ; 2,3 \mathrm{~Gy} ; 3$, $10 \mathrm{~Gy}+1 \mathrm{TC} ; 4,10 \mathrm{~Gy} ; 5,20 \mathrm{~Gy} ; 6,30 \mathrm{~Gy} ; 7,30 \mathrm{~Gy}$. (B) 1,0 Gy+1 TC; 2, 2 Gy; 3,3 Gy; 4, 10 Gy; 5, 20 Gy; 6, 30 Gy; 7, 40 Gy; 8, 40 Gy. (C) 1, 0 Gy; 2, 3 Gy; 3, $6 \mathrm{~Gy} ; 4,10 \mathrm{~Gy} ; 5,20 \mathrm{~Gy} ; 6,30 \mathrm{~Gy} ; 7,40 \mathrm{~Gy} ; 8,50 \mathrm{~Gy} ; 9,50 \mathrm{~Gy}$. (D) 1, 0 Gy; 2 , 3 Gy; 3, 6 Gy; 4, 10 Gy; 5, 20 Gy; 6, 20 Gy+1 TC; 7, 30 Gy; 8, 40 Gy; 9, 50 Gy. $1 \mathrm{TC}$, one course of paclitaxel-cisplatin chemotherapy. Ratio, gray scale ratio of IER5/ $\beta$-actin. the protein expression level of IER 5 in $\geq 20$ Gy group was significantly higher than that in the other two groups $(\geq 20 \mathrm{~Gy}$ group, $1.300 \pm 0.376$; compared with $<20$ Gy group, $\mathrm{P}=0.002$; compared with 0 Gy group, $\mathrm{P}=0.003$; Table II). However, no significant difference was observed between the $0 \mathrm{~Gy}$ and $<20$ Gy groups (0 Gy group, $0.653 \pm 0.154 ;<20$ Gy group, $0.847 \pm 0.359 ; \mathrm{P}=0.349$; Table II). In addition, the results of the correlation analysis indicated that there was a significant positive correlation between the protein expression of IER 5 and the dose of radiation $(\mathrm{r}=0.573, \mathrm{P}<0.0001)$.

Correlation between expression of IER 5 and clinical outcomes of radiotherapy. Based on the mRNA and protein expression of IER5, the patients were divided into two groups: a low IER5 expression group (including the $0 \mathrm{~Gy}$ group and $<20 \mathrm{~Gy}$ group) and a high IER 5 expression group (including the $\geq 20$ Gy group). There were 36 patients in the low expression group and 33 patients in the high expression group. The results of the Chi-square test indicated that there was no significant difference between the two groups with regard to the survival rate (low expression group, 93.3\%; high expression group, 96.8\%; Chi-square test; $\mathrm{P}=0.490$ ) and recurrence rate (low expression group, $6.67 \%$; high expression group, $6.25 \%$; Chi-square test; $\mathrm{P}=0.914)$.

\section{Discussion}

IER5 is possibly an intronless gene, which encodes a transcript of 2110 nucleotides in length and shares a number of nucleic acid and protein homologies with other members of the growth factor-inducible genes $(18,19)$. Previous studies have reported that the expression of IER 5 may be induced by radiation in cells including HeLa cells, human lymphoblastoid cells, HepG2 and A549 (20-23). In this study, we investigated 
the radiation-induced mRNA and protein expression levels of IER5 in cervical cancer. The results indicated that the protein and mRNA expression of IER5 in the $\geq 20$ Gy group was significantly higher than that in the other two groups, which suggested that the expression of IER 5 in cervical cancer tissue was significantly increased after receiving radiotherapy at a dose of $\geq 20$ Gy. Moreover, the mRNA and protein expression of IER 5 was significantly positively correlated with the radiation dose. The results suggested that radiotherapy could induce the upregulation of mRNA and protein expression of IER5 in cervical cancer and that this induction was dose-dependent. In addition, there was no significant difference between the low IER 5 expression group and high IER 5 expression group in terms of the survival and recurrence rate. This suggested that the radiation-induced upregulation of IER5 expression was not associated with the clinical outcomes of radiotherapy in cervical cancer.

The results of this study were consistent with those of Kis et al, who observed that the mRNA expression of IER5 was dependent on radiation dose and time (24). Moreover, the dose- and time-dependent patterns of radiation-induced expression of IER 5 varied with cell types (18). This indicated that there was a complex transcriptional responsiveness of IER 5 to ionizing radiation. In addition, in an study of estrogen-dependent gene expression in the rat uterus, investigators identified that the expression of IER5 would decrease following ovariectomy but increase following an injection of estrogen (25). In addition, Tavakoli et al observed that the radiation-induced transcription alterations of IER5 were associated with gender (13). Given that cervical cancer is a female malignancy, we inferred that the radiation-induced expression of IER 5 might be associated with the secretion of estrogen in the cervical cancer tissues.

Furthermore, the radiation-induced expression of IER5 may be associated with the radiosensitivity of cervical cancer. Ding et al observed that suppression of IER 5 potentiated radiation-induced arrest at the $\mathrm{G} 2 / \mathrm{M}$ transition and led to an increase in the fraction of S-phase cells (11). It was also reported that low-dose hyper-radiosensitivity is linked to the early G2/M checkpoint through the damage response of G2-phase cells (26-28). Thus, we inferred that the radiation-induced expression of IER 5 was associated with the radiosensitivity of cervical cancer via the damage response of G2-phase cells. Further studies are required to prove this speculation.

Certain limitations must be noted in this study. Firstly, due to the lack of detailed information on follow-up, survival curves could not be obtained. More studies should be carried out to investigate the correlation between the expression of IER 5 and the efficacy of radiotherapy. Secondly, three of the patients were treated with a combination of radiotherapy and chemotherapy, which may affect the results of this study. Thus, further studies are required to verify the results of this study.

In conclusion, we observed that radiotherapy could induce the upregulated expression of IER5 in cervical cancer and that the induction was dependent on the dose of radiation. IER5 may play crucial roles in the radiosensitivity of cervical cancer cells. This study provides data for the investigation of the radiosensitivity mechanism of cervical cancer, which is the main constraint in the efficacy of radiotherapy. However, no association between the radiation-induced expression of IER5 and the clinical outcomes of radiotherapy in cervical cancer was identified in this study. The results suggested that although IER5 may be a key gene in the radiosensitivity mechanism of cervical cancer, there may be no direct association between the expression of IER 5 and clinical efficacy of radiotherapy. The possible roles of IER5 in the radiosensitivity mechanism of cervical cancer still require further investigation.

\section{Acknowledgements}

This study was supported by grants from the National Natural Science Foundation of China (no. 30770573 and 31170806), Beijing Municipal Education Commission (Science and Technology for Development Program Km7092013) and the Key Project of Science and Technology of Shenyang, Liaoning, China (F12193948).

\section{References}

1. Walboomers JM, Jacobs MV, Manos MM, Bosch FX, Kummer JA, Shah KV, Snijders PJ, Peto J, Meijer CJ and Muñoz N: Human papillomavirus is a necessary cause of invasive cervical cancer worldwide. J Pathol 189: 12-19, 1999.

2. Arbyn M, Castellsagué X, De Sanjose S, Bruni L, Saraiya M, Bray $\mathrm{F}$ and Ferlay J: Worldwide burden of cervical cancer in 2008. Ann Oncol 22: 2675-2686, 2011.

3. Forouzanfar MH, Foreman KJ, Delossantos AM, Lozano R, Lopez AD, Murray CJ and Naghavi M: Breast and cervical cancer in 187 countries between 1980 and 2010: A systematic analysis. Lancet 378: 1461-1484, 2011.

4. Jemal A, Bray F, Center MM, Ferlay J, Ward E and Forman D: Global cancer statistics. CA Cancer J Clin 61: 69-90, 2011.

5. Siegel R, Ma J, Zou Z and Jemal A: Cancer statistics, 2014. CA Cancer J Clin 64: 9-29, 2014.

6. Siegel R, Naishadham D and Jemal A: Cancer statistics, 2013. CA Cancer J Clin 63: 11-30, 2013.

7. Jemal A, Siegel R, Ward E, Murray T, Xu J and Thun MJ: Cancer statistics, 2007. CA Cancer J Clin 57: 43-66, 2007.

8. Tanderup K, Georg D, Pötter R, Kirisits C, Grau C and Lindegaard JC: Adaptive management of cervical cancer radiotherapy. Semin Radiat Oncol 20: 121-129, 2010.

9. Barillot I, Horiot JC, Maingon P, Truc G, Chaplain G, Comte J and Brenier JP: Impact on treatment outcome and late effects of customized treatment planning in cervix carcinomas: baseline results to compare new strategies. Int J Radiat Oncol Biol Phys 48: 189-200, 2000.

10. Kitahara O, Katagiri T, Tsunoda T, Harima Y and Nakamura Y: Classification of sensitivity or resistance of cervical cancers to ionizing radiation according to expression profiles of 62 genes selected by cDNA microarray analysis. Neoplasia 4: 295-303, 2002.

11. Ding KK, Shang ZF, Hao C, Xu QZ, Shen JJ, Yang CJ, Xie YH, Qiao C, Wang Y, Xu LL and Zhou PK: Induced expression of the IER5 gene by gamma-ray irradiation and its involvement in cell cycle checkpoint control and survival. Radiat Environ Biophys 48: 205-213, 2009.

12. Yili Z, Xiaoyan H, Hongwen D, Yun Z, Xin C, Peng W and Youmin G: The value of diffusion-weighted imaging in assessing the ADC changes of tissues adjacent to breast carcinoma. BMC Cancer 9: 18, 2009.

13. Tavakoli H, Manoochehri M, Modarres Mosalla SM, Ghafori M and Karimi AA: Dose-dependent and gender-related radiation-induced transcription alterations of Gadd45a and Ier5 in human lymphocytes exposed to gamma ray emitted by (60)Co. Radiat Prot Dosimetry 154: 37-44, 2013.

14. Long XH, Zhao ZQ, He XP, et al: Dose-dependent expression changes of early response genes to ionizing radiation in human lymphoblastoid cells. Int J Mol Med 19: 607-615, 2007.

15. Lanciano RM, Won M and Hanks GE: A reappraisal of the international federation of gynecology and obstetrics staging system for cervical cancer. A study of patterns of care. Cancer 69: 482-487, 1992.

16. Martel F, Gründemann D and Schömig E: A simple method for elimination of false positive results in RT-PCR. J Biochem Mol Biol 35: 248-250, 2002. 
17. Aune TM, Penix LA, Rincón MR and Flavell RA: Differential transcription directed by discrete gamma interferon promoter elements in naive and memory (effector) CD4 T cells and CD8 T cells. Mol Cell Biol 17: 199-208, 1997.

18. Williams M, Lyu MS, Yang YL, Lin EP, Dunbrack R, Birren B, Cunningham $\mathrm{J}$ and Hunter $\mathrm{K}$ : Ier5, a novel member of the slow-kinetics immediate-early genes. Genomics 55: 327-334, 1999.

19. Gregory S, Barlow K, Mclay K, Kaul R, Swarbreck D, Dunham A, Scott CE, Howe KL, Woodfine K, Spencer CC, et al: The DNA sequence and biological annotation of human chromosome 1 . Nature 441: 315-321, 2006.

20. Li XN, Li L, Yang CJ, et al: The influence of IER5 gene on the radiosensitivity of HeLa cells. Prog Biochem Biophys 36: 847-853, 2009

21. Lu WY, Liu ZX, Li L, Ma HP, Zheng KY and Ding KK: Quantitation analysis to radiation effect on tumor cell by MATLAB. Chinese Journal of Medical Physics 5: 024, 2010.

22. Guo WF, Lin RX, Huang J, Zhou Z, Yang J, Guo GZ and Wang SQ: Identification of differentially expressed genes contributing to radioresistance in lung cancer cells using microarray analysis. Radiat Res 164: 27-35, 2005.

23. Wang H, Long X, Sun ZZ, Rigaud O, Xu QZ, Huang YC, Sui JL, Bai B and Zhou PK: Identification of differentially transcribed genes in human lymphoblastoid cells irradiated with $0.5 \mathrm{~Gy}$ of gamma-ray and the involvement of low dose radiation inducible CHD6 gene in cell proliferation and radiosensitivity. Int J Radiat Biol 82: 181-190, 2006.
24. Kis E, Szatmári T, Keszei M, Farkas R, Esik O, Lumniczky K, Falus A and Sáfrány G: Microarray analysis of radiation response genes in primary human fibroblasts. Int $\mathrm{J}$ Radiat Oncol Biol Phys 66: 1506-1514, 2006.

25. Wu X, Pang ST, Sahlin L, Blanck A, Norstedt G and Flores-Morales A: Gene expression profiling of the effects of castration and estrogen treatment in the rat uterus. Biol Reprod 69: 1308-1317, 2003.

26. Fernet M, Mégnin-Chanet F, Hall J and Favaudon V: Control of the $\mathrm{G} 2 / \mathrm{M}$ checkpoints after exposure to low doses of ionising radiation: Implications for hyper-radiosensitivity. DNA Repair (Amst) 9: 48-57, 2010

27. Marples B, Wouters B, Collis S, Chalmers A and Joiner MC: Low-dose hyper-radiosensitivity: a consequence of ineffective cell cycle arrest of radiation-damaged G2-phase cells. Radiat Res 161: 247-255, 2004.

28. Krueger SA, Wilson GD, Piasentin E, Joiner MC and Marples B: The effects of G2-phase enrichment and checkpoint abrogation on low-dose hyper-radiosensitivity. Int J Radiat Oncol Biol Phys 77: 1509-1517, 2010. 